\title{
Effects of Addition of Alkaline Earth Metal-Beryllium on the Dissolution Behaviour of Aluminium-Zinc Alloy
}

\author{
K. Vijayarani, ${ }^{a,}{ }^{*}$ M. Vishnu Devan ${ }^{a}$ and R. Natarajan ${ }^{b}$ \\ ${ }^{a}$ P.G.\& Research Department of Chemistry, Government Arts College, Karur, \\ 690005 Tamil Nadu, India \\ ${ }^{b}$ P.G.\& Research Department of Chemistry, Alagappa Government Arts College, Karaikudi, \\ 630003 Tamil Nadu, India
}

Received September 1, 2016; accepted November 22, 2016

\begin{abstract}
This work has investigated the effect of addition of the Be alkaline earth metal on the dissolution behaviour of the Al- $\mathrm{Zn}$ alloy anode. Corrosion experiments were mounted to determine the optimal effect of an alkaline earth metal on the efficiencies of the aluminium alloy anodes. The corroded and unexposed sample surfaces were subject to microstructural characterization by using scanning electron microscopy and X-ray diffraction techniques. Al-Zn alloy doped with $1-5 \%$ by weight of beryllium was prepared to determine the effect on the anode efficiency in chloride environment. The different microstructure of the evolved Al-Zn alloy was correlated with the anode efficiencies. The obtained results showed that the anode efficiency of the Al- $\mathrm{Zn}$ alloy increased with the beryllium incorporation concentration. Al-Zn-Be-3\% exhibits the better performance in terms of anode efficiency. The microstructure of the Al-Zn-Be alloy revealed increased distribution of beryllium globules and a breakdown of passive alumina film network on the anode surfaces, thus improving the anode efficiency.
\end{abstract}

Keywords: corrosion; sacrificial anode; aluminium alloy; alkaline earth metal; efficiency and microstructures.

\section{Introduction}

Corrosion is the deterioration of materials with its environment, and it can be mitigated by various techniques. Cathodic protection is one of the techniques that are mainly employed in industries and marine environments to control corrosion. Cathodic protection is greatly employed to protect oil pipelines, marine and some industrial structures. In this system, particularly sacrificial anode system, electric current is applied by using dissimilar metals with the driving voltage created by the potential generation between the two metals in an electrolyte system. The electrochemical behaviour of sacrificial anode materials is of vital importance for

\footnotetext{
* Corresponding author. E-mail address: vijayaraninatarajan@gmail.com
} 
the reliability and efficiency of cathodic protection systems (Joan Genesca et al., 2000).

Generally, metals such as aluminium, zinc and magnesium are employed as anode materials in sacrificial cathodic protection systems. The limitation of usage of magnesium based alloy systems is their low efficiency, which gives rise to loss of substantial parts of the required current capacity. It is affirmed that aluminium is the most preferred sacrificial anode for controlling and preventing corrosion in marine environments. Aluminium anodes are also favoured over zinc anodes for the cathodic protection of offshore structures, especially in deep water exploration, because they are lighter and less expensive. Evaluation of the performance of aluminium anodes is necessary to achieve the most cost-effective sacrificial cathodic protection design. The usefulness of pure aluminium as an anode material in seawater is significantly reduced, due to the formation of a protective oxide film, which limits both its current and potential output. In order to improve the efficiency of aluminium anodes, they are typically alloyed with other elements to encourage depassivation (breakdown of the oxide film) and/or shift the operating potential of the metal to a more electronegative direction. The alloying elements used to accomplish this are referred as depassivators and modifiers. Modifiers that have been used in practice include zinc, magnesium, barium, and cadmium. Also, the depassivators commonly used are indium, mercury, tin and rarely gallium, titanium and thallium. However, these metals are highly toxic in marine environment. Hence, the metal modifier used should possess eco-friendly as well as good activation for an improved performance as sacrificial anodes.

Most of the efforts in this field were carried out using aluminium rich zinc sacrificial anodes, and the concentration of zinc in aluminium alloy sacrificial anodes has been optimized to $5 \mathrm{wt} \%$, due to high improvement in metallurgical and electrochemical properties of the alloy through the formation of $\beta$-phase (Lyublinskii, 1973). The addition of alloying elements like tin and indium shifts the potential of the anode in the negative direction and helps in keeping the anode active (Reboul et al., 1982). Modification of $\mathrm{Al}+5 \% \mathrm{Zn}$ alloy anode is essential, due to non-columbic loss and low galvanic efficiency (Li et al., 2005). The base alloy chosen for the present work is $\mathrm{Al}+5 \% \mathrm{Zn}$, which has been proved to be the most suitable and efficient material for cathodic protection application (Shibli et al., 2005). Considering Al-Zn binary system, zinc is concentrated in interdentritic or grain boundaries, and several theories have been proposed to explain the influence of zinc on the activation of the dissolution of $\mathrm{Al}$ in chloride aqueous environment (Manoz et al., 2001). 5\% $\mathrm{Zn}$ is the optimized concentration as a second major element with aluminum for the newly developed aluminum alloy used in the cathodic protection application in saline water environment (Lyublinskii, 1973; Haijing et al., 2013; Shibli et al., 2004; Jingling et al., 2009; Khireche et al., 2014).

Extensive studies on the surface modification of Al alloys by binary or ternary systems have been reported (Mohammad et al., 2011; Sina et al., 2006; Gudic et al., 2010; Alvarez et al., 2005; Jiuba et al., 2011; Mathiyarasu et al., 2001). Hence, the uniform and homogeneous distribution of other metals on aluminium 
alloy effectively suppresses the formation of passive $\mathrm{Al}_{2} \mathrm{O}_{3}$ on the $\mathrm{Al}$ alloy anode systems, which in turn activates the anode i.e., alloying of the third metal on the aluminium-zinc alloy.

To the best of our knowledge, the effects of the addition of an alkaline earth metal, particularly beryllium, have not been studied as a modifier in Al-Zn binary base alloy. Herein, we have made an attempt to investigate the dissolution behaviour of Al-Zn-Be ternary alloy, and results are compared with Al-Zn binary base alloy. In particular, the influence of the addition of beryllium on the electrochemical behaviour of the binary alloy (Al-Zn) and the obtained results are discussed.

\section{Experimental details \\ Alloy electrode preparation}

$\mathrm{Al}-\mathrm{Zn}-\mathrm{Be}$ based ternary alloy electrodes were prepared by alloy casting method and the compositions in terms of wt. $\%$ are given in Table 1. Commercially available pure aluminium (99.99\% NALCO), zinc $(99.99 \%)$ and beryllium (99.9\%) received from Otto Chemie Ltd. were the raw materials used for casting the alloy anode. The materials were cut into pieces, weighed and melted in a graphite crucible in an automated vacuum furnace under argon atmosphere at 650 ${ }^{\circ} \mathrm{C}$. The mixture was gently stirred using a carbon bar to obtain a homogeneous mixture, as well as heat dissipation. The molten alloy was poured in a preheated cast iron die of $300 \times 10 \mathrm{~mm}$, and allowed to cool in air. The obtained Al-Zn-Be ternary alloy, in the form of rod of $1 \mathrm{~cm}$ diameter $\mathrm{x} 10 \mathrm{~cm}$ long, is employed for evaluation studies after machining. Actual composition of the casted alloy was determined by Atomic Absorption Spectrometer (iCE Thermo Scientific), and is given in Table 1.

Table 1. Composition of $\mathrm{Al}-\mathrm{Zn}-\mathrm{Be}$ alloy in wt. \% determined using Atomic Absorption Spectrometer (iCE Thermo Scientific).

\begin{tabular}{llccccccc}
\hline Composition & \multicolumn{1}{c}{ Al } & \multicolumn{2}{c}{ Zn } & Be & Fe & Cu & Si & \multicolumn{1}{c}{ Sn } \\
\hline Al 95\%-Zn 5\% & Remainder & 4.763 & ------ & 0.215 & 0.212 & 0.143 & 0.124 \\
Al-Zn-Be 1\% & Remainder & 4.647 & 0.964 & 0.195 & 0.187 & 0.253 & 0.109 \\
Al-Zn-Be 2\% & Remainder & 4.322 & 1.864 & 0.183 & 0.196 & 0.271 & 0.186 \\
Al-Zn-Be 3\% & Remainder & 4.821 & 2.653 & 0.162 & 0.147 & 0.223 & 0.144 \\
Al-Zn-Be 4\% & Remainder & 4.214 & 3.441 & 0.172 & 0.163 & 0.196 & 0.172 \\
Al-Zn-Be 5\% & Remainder & 4.976 & 4.306 & 0.131 & 0.182 & 0.214 & 0.115 \\
\hline
\end{tabular}

\section{Physico-chemical evaluation}

The Al-Zn-Be ternary alloy of varying amounts of beryllium was polished using different grades of emery paper, and cleaned with dilute $\mathrm{NaOH}$, followed by rinsing with distilled water. The microscopic structures such as grain size, grain 
boundaries and morphology of the $\mathrm{Al}-\mathrm{Zn}-\mathrm{Be}$ alloy anodes were characterized using a scanning electron microscope (Hitachi-model S-3000N). X-ray diffraction (XRD) (PAnalytical, XPert Pro using High score Plus software) study was carried out to characterize the phase structure of the prepared $\mathrm{Al}-\mathrm{Zn}-\mathrm{Be}$ alloy.

\section{Electrochemical characterization}

Determination of galvanic efficiency

$\mathrm{Al}-\mathrm{Zn}-\mathrm{Be}$ alloy of varying beryllium content was used as anode $\left(10 \mathrm{~cm}^{2}\right)$, and mild-steel was used as cathode (surface area $100 \mathrm{~cm}^{2}$ ). These electrodes are immersed in aerated $3 \% \mathrm{NaCl}$ solution at $28 \pm 2{ }^{\circ} \mathrm{C}$ for a period of 96 hours under static condition as per DNV standard (Det Norske Veritas Industry (Hovik, 1993). Different current densities were employed ca. 1.5, 0.4, 4.0, $1.5 \mathrm{~mA} / \mathrm{cm}^{2}$, and after immersion, these specimens were cleaned using a hot mixture of $20 \mathrm{~g}$ potassium dichromate and $50 \mathrm{~mL}$ phosphoric acid in 1 liter water at 70 to $80{ }^{\circ} \mathrm{C}$ for 10 minutes.

$$
\text { Electrochemical efficiency }(\mathrm{Ah} / \mathrm{kg}) \quad \varepsilon=(\mathrm{C} \times 1000) / \Delta \mathrm{w}
$$

where $\mathrm{C}$ is the total current impressed in $\mathrm{Ah}$ and $\Delta \mathrm{w}$ is the weight loss in $\mathrm{g}$.

\section{Polarization studies}

Potentiodynamic polarization studies were carried out in $3.0 \% \mathrm{NaCl}$ solution under aerated condition. A saturated calomel electrode (SCE), Pt foil and Al-ZnBe alloy having $2 \mathrm{~cm}^{2}$ and $1 \mathrm{~cm}^{2}$ exposure area were used as reference, counter and working electrodes, respectively. In order to attain equilibrium, a time interval of 30-45 min was maintained, and the open circuit potential (OCP) was measured before performing the potentiodynamic polarisation studies. Both anodic and cathodic polarization curves were potentiodynamically recorded using potentiostat / galvanostat (ACM instrument, UK). The corrosion kinetic parameters such as $\mathrm{I}_{\text {corr, }} \mathrm{E}_{\mathrm{corr}}$, ba (anodic Tafel slope) and bc (cathodic Tafel slope) were measured using the built-in software (ACM inbuilt software). The following experimental conditions are maintained: sweep rate $1 \mathrm{mV} \cdot \mathrm{sec}^{-1}$; potential range $-200 \mathrm{mV}$ to $+200 \mathrm{mV}$ from OCP; and a constant temperature of $28 \pm 2{ }^{\circ} \mathrm{C}$.

\section{Self-corrosion test}

$\mathrm{Al}-\mathrm{Zn}-\mathrm{Be}$ alloy was immersed in $3 \% \mathrm{NaCl}$ solution for a period of 15 days. The electrolyte was maintained under static condition at $28 \pm 2{ }^{\circ} \mathrm{C}$. After exposure, the anodes were cleaned using potassium dichromate + phosphoric acid mixture at 70 to $80{ }^{\circ} \mathrm{C}$ for 10 minutes. The anodes were rinsed in distilled water, dried and then weighed. The difference in weight before and after immersion was used to calculate the self-corrosion.

$$
\text { Corrosion rate }=\frac{\text { Weight loss }\left(\mathrm{g} \mathrm{cm}^{-1} \mathrm{~h}^{-1}\right)}{\text { Surface area } \mathrm{x} \text { time }}
$$


Average corrosion rate (mmpy) of Al alloy anode was calculated as

$$
\text { Corrosion rate }=\left(87.6 \times 10^{4} \times W\right) /(A \times T \times D)
$$

where, $\mathrm{T}$ is time of exposure in hours, $\mathrm{A}$ is the area in $\mathrm{cm}^{2}, \mathrm{~W}$ is the mass loss in $\mathrm{g}$, and $\mathrm{D}$ is the density in $\mathrm{g} / \mathrm{cm}^{3}$.

\section{Study of OCP and CCP variation}

While observing the open circuit potential (OCP), the potential difference between the Al-Zn-Be alloy samples, with respect to standard calomel electrode (SCE), was continuously monitored for a period of 15 days, immersed in $3 \%$ $\mathrm{NaCl}$ maintained at $28 \pm 2{ }^{\circ} \mathrm{C}$. The closed circuit potential (CCP) of the alloy was monitored after coupling with mild steel cathodes, having the surface area in the ratio of 1:10. The current density generated at the anode surface was maintained constant during $\mathrm{CCV}$ measurements using a controlled variable resistance (NACE, 1998).

\section{Study of electrochemical impedance}

Electrochemical impedance spectroscopy (EIS) was carried out using an electrochemical analyzer (ACM instrument, UK). The electrolyte used was $3.0 \% \mathrm{NaCl}$, and SCE, Pt foil, and the Al-Zn-Be alloy anode having $2 \mathrm{~cm}^{2}$ and 1 $\mathrm{cm}^{2}$ surface area were used as reference, counter and working electrodes, respectively. The impedance analysis was carried out at the frequency range of 1 $\mathrm{MHz}$ to $0.1 \mathrm{~Hz}$, with reference to OCP. Corrosion current ( $\mathrm{i}_{\text {corr }}$ ), corrosion rate, solution resistance $\left(R_{s}\right)$, charge transfer resistance $\left(R_{c t}\right)$ and double layer capacitance values $\mathrm{C}_{\mathrm{dl}}$ were calculated from the impedance analysis.

\section{Results and discussion}

\section{Alloying characteristics of the anode}

Fig. 1 shows that the SEM micrograph of the base alloy $(\mathrm{A} 1+5 \% \mathrm{Zn})$ exhibited concrete like morphology with minimum amount of pores. From this texture it is very difficult to understand the clear precipitation or segregation of $\mathrm{Al}+5 \% \mathrm{Zn}$ alloy matrix, which is uniformly distributed throughout the constituent. This observation revealed that the homogeneity of the base alloy is the same as it could also be seen at higher magnifications. Fig. 1.b-f shows the micrograph of the beryllium incorporated $\mathrm{Al}+5 \% \mathrm{Zn}$ alloy matrix. When beryllium is introduced in the alloy matrix the porosity of this one increases. Further, diffused boundaries and parts of it containing regions of bright precipitate are also observed. It is projected that beryllium addition leads to interdendritic boundaries, since it is the most insoluble metal in the Al- $\mathrm{Zn}$ alloy, and this precipitate is uniformly scattered along the entire matrix. Further, addition of beryllium with varying content leads to flaky/plate like structures that may lead to a uniform dissolution of the alloy matrix.

Further, the crystal structural properties of the aluminium-zinc anode materials with varying beryllium addition were characterized and confirmed by using $\mathrm{X}$ ray diffraction measurement. 


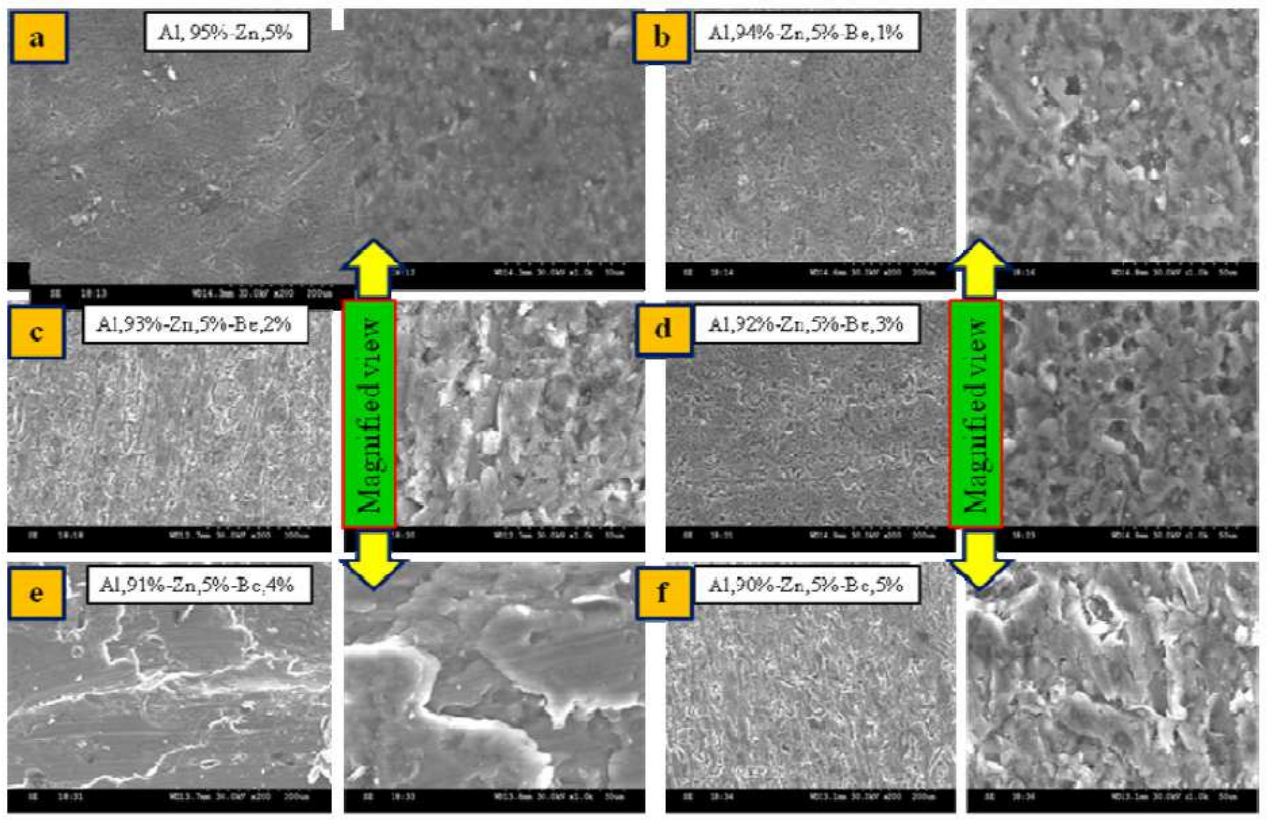

Figure 1. SEM photograph of pure $\mathrm{Al}+5 \% \mathrm{Zn}$ alloy anodes with activator (a: $0 \% \mathrm{Be}, \mathrm{b}$ : $1 \% \mathrm{Be}, \mathrm{c:} 2 \% \mathrm{Be}, \mathrm{d}: 3 \% \mathrm{Be}, \mathrm{e}: 4 \% \mathrm{Be}$, and f: $5 \% \mathrm{Be})$.

In Fig. 2, the peaks observed at around $2 \theta=38^{\circ}, 46^{\circ}$ correspond to $\mathrm{Zn}(100)$ and (101) planes, respectively. In addition to this, the peaks appeared at $2 \theta=65$ and $78^{\circ}$ are attributed to different forms of aluminium, $\left[\alpha-\mathrm{Al}_{2} \mathrm{O}_{3}\right]$ with an indexing of (220) (311), respectively.

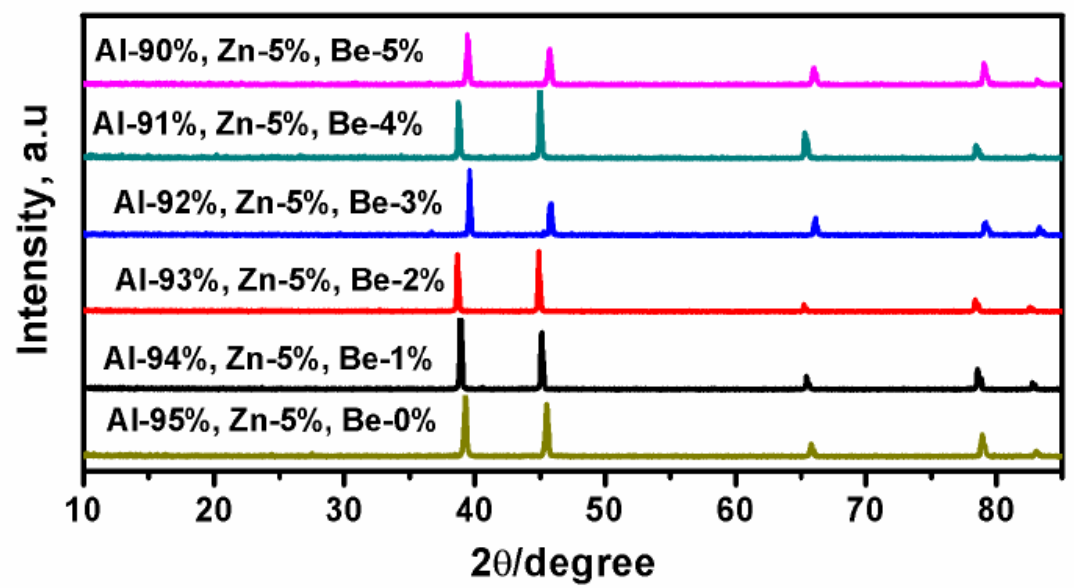

Figure 2. XRD patterns of aluminium-zinc-beryllium alloy anodes.

However, after the addition of $\mathrm{Be}$ into the $\mathrm{Al}$ and $\mathrm{Zn}$ base alloy, major peaks of $\mathrm{Al}$ and $\mathrm{Zn}$ are slightly shifted, which strongly signifies the formation of intermetallic compounds.

\section{Evaluation of galvanic performance}

The CCP of $\mathrm{Al}+5 \% \mathrm{Zn}$ alloy anode with varying amount of addition of beryllium were compared in Table 2. An active CCP is desirable, since a relatively noble potential could indicate the presence of passivation. The Al+5\% $\mathrm{Zn}$ alloy anodes with $3 \%$ beryllium incorporation showed a more cathodic CCP value of -1.014 
V. Anodes must also possess high galvanic efficiency, in order to avoid frequent anode replacement. Duplicate experiments were conducted, and the average efficiency of 1, 2, 3, 4 and 5\% addition of beryllium were observed as $50.96 \%$, $68.0 \%, 75.57 \%, 78.30 \%$ and $90.19 \%$, respectively, and the efficiency of $\mathrm{Al}+5 \% \mathrm{Zn}$ anode was $58.42 \%$. Thus, the galvanic performance of anodes was much improved with the incorporation of beryllium in the alloy matrix. The overall galvanic performances of the beryllium incorporated anodes are compared in Table 2. It is clear that lower self-corrosion values were observed for $2 \%$ of beryllium incorporation. The reduction in self-corrosion values of the anodes could be attributed to the reduction in grain boundary corrosion. Thus, the beryllium offers better reinforcement to the $\mathrm{Al}+5 \% \mathrm{Zn}$ alloy matrix, causing a very low dissolution during long-term exposure.

Table 2. The galvanic performance of $\mathrm{Al}+5 \mathrm{wt} \% \mathrm{Zn}$ incorporated with beryllium (electrolyte: $3 \% \mathrm{NaCl}$, temp: $28 \pm 2{ }^{\circ} \mathrm{C}$, stagnant condition).

\begin{tabular}{|c|c|c|c|c|c|c|c|}
\hline \multirow{2}{*}{$\begin{array}{c}\text { Amount of } \\
\text { beryllium } \\
\text { added } \\
\text { Wt\% }\end{array}$} & \multirow{2}{*}{$\begin{array}{l}\text { OCP V } \\
\text { vs. SCE }\end{array}$} & \multicolumn{4}{|c|}{$\begin{array}{l}\text { CCP V vs. SCE at different current } \\
\text { densities }\left(\mathrm{mA} \cdot \mathrm{cm}^{-2}\right)\end{array}$} & \multirow{2}{*}{$\begin{array}{l}\text { Self-corrosion } \\
\times 10^{-6} \mathrm{~g} \mathrm{~cm}^{-2}\end{array}$} & \multirow{2}{*}{$\begin{array}{l}\text { Efficiency } \\
\quad( \pm 1 \%)\end{array}$} \\
\hline & & 1.5 & 0.4 & 4.0 & 1.5 & & \\
\hline 0 & -0.959 & -0.963 & -0.974 & -0.985 & -0.996 & 47.71 & 58.42 \\
\hline 1 & -0.911 & -0.980 & -1.026 & -0.008 & -1.003 & 42.23 & 50.96 \\
\hline 2 & -0.919 & -0.959 & -1.014 & -1.014 & -1.014 & 23.52 & 68.00 \\
\hline 3 & -0.956 & -1.014 & -0.953 & -0.953 & -0.953 & 38.43 & 75.57 \\
\hline 4 & -0.963 & -0.953 & -1.004 & -1.004 & -1.004 & 24.53 & 78.30 \\
\hline 5 & -0.977 & -0.961 & -0.983 & -0.950 & -0.965 & 33.23 & 90.19 \\
\hline
\end{tabular}

\section{Potentiodynamic polarization}

The effect of beryllium addition on the polarization behaviour of aluminium alloy anode is shown in Fig. 3, and the corresponding polarization parameters derived are given in Table 3. Addition of beryllium shifts the corrosion potential to more negative values, which is a prerequisite of anode materials for cathodic protection systems. Introduction of beryllium decreased the polarization resistance $\left(R_{p}\right)$ and increased the corrosion potential $E_{c o r r}$ in the negative direction. For $5 \%$ beryllium incorporated $\mathrm{Al}$ alloy anode, the corrosion rate and current were found to maximum, and polarisation resistance is found to a minimum value. Though the potential variations are not more than few millivolts, they can be compared, and from these results, the optimum concentration of beryllium was revealed. The above results revealed that addition of $2 \%$ beryllium imparted better anode performance.

The OCP of Be incorporated anode showed similar potential value with bare anode. The initial OCP value of $\mathrm{Al}+5 \% \mathrm{Zn}$ anode was found to $-0.959 \mathrm{~V}$. After 2 days immersion, the potential shifts to more anodic direction. The OCP values of $4 \%$ and $5 \%$ beryllium incorporated anodes resulted in a steady state behavior. Conversely, with time, the OCP values slowly shifted to a more cathodic region. 
Therefore, OCP cannot be considered as a sole factor determining the anodic performance. On the contrary, the CCP value exhibited a steady performance throughout the test period at different impressed current densities, which indicates that beryllium acts as a good moderator and does not hinder the polarization behavior of the base alloy. From Fig. 3, it is observed that there is no remarkable change in the potentiodynamic polarization behaviour, however, addition of beryllium shifts the corrosion potential towards cathodic direction. In the case of $\mathrm{Al}+5 \% \mathrm{Zn}$ alloy, passivation behaviour was observed in the anodic slope region at a current value of $1 \mathrm{~mA} \cdot \mathrm{cm}^{-1}$. With $5 \%$ beryllium addition, the passivation shifted to a potential value of $-960 \mathrm{mV}$; with $4 \%$ beryllium addition, it completely disappears at the anodic region. In general, the added beryllium in all compositions shifts corrosion potential towards a more cathodic potential, compared to the base $\mathrm{Al}+5 \% \mathrm{Zn}$ alloy.

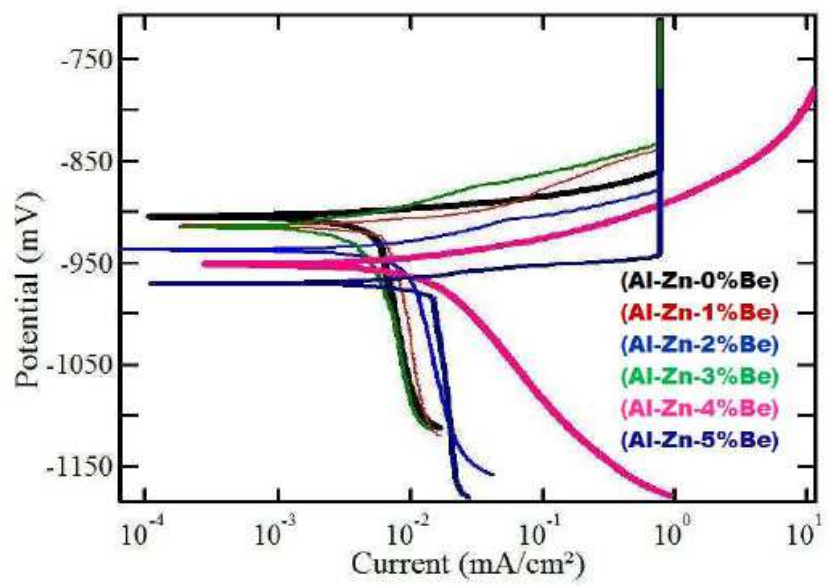

Figure 3. Polarization behavior of different composition of beryllium incorporated with $\mathrm{Al}+5 \% \mathrm{Zn}$ alloy.

\section{Electrochemical impedance spectroscopy (EIS) measurements}

AC impedance studies were carried out to obtain information about the electrochemical and physico-chemical phenomena associated with the electrode reactions during galvanic dissolution process.

Table 3. Potentiodynamic polarization parameters for different compositions of beryllium incorporated with $\mathrm{Al}+5 \% \mathrm{Zn}$ alloy.

\begin{tabular}{|c|c|c|c|c|c|c|}
\hline $\begin{array}{c}\% \text { of } \\
\text { Beryllium }\end{array}$ & $\begin{array}{l}\text { Ecorr }_{\text {con }} \\
\text { (V) }\end{array}$ & $\begin{array}{c}\mathrm{I}_{\text {corr }}\left(\mathrm{A} \cdot \mathrm{cm}^{-2}\right) \\
\times 10^{-3}\end{array}$ & $\begin{array}{c}\mathbf{b}_{\mathbf{a}} \\
\left(\mathbf{m V} / \mathbf{d e c}^{-1}\right)\end{array}$ & $\begin{array}{c}\mathbf{b}_{\mathrm{c}} \\
\left(\mathrm{mV} / \mathrm{dec}^{-1}\right)\end{array}$ & $\begin{array}{c}\mathrm{Rp} \\
\left(\mathrm{X} \mathrm{cm^{2 } )}\right)\end{array}$ & $\begin{array}{c}\text { Corr. Rate } \\
\text { MPY }\end{array}$ \\
\hline 0 & -0.914 & 0.7868 & 30 & 91 & 783.2 & 0.0856 \\
\hline 1 & -0.922 & 0.3118 & 21 & 115 & 756.4 & 0.03395 \\
\hline 2 & -0.964 & 0.4432 & 21 & 110 & 182.2 & 0.04827 \\
\hline 3 & -0.938 & 0.5610 & 29 & 97 & 228.6 & 0.06110 \\
\hline 4 & -0.943 & 0.2285 & 31 & 92 & 436.9 & 0.0248 \\
\hline 5 & -0.951 & 0.8011 & 25 & 72 & 335.3 & 0.0872 \\
\hline
\end{tabular}

The EIS plots of aluminium alloy anodes incorporated with different amounts of beryllium are shown in Fig. 4. The impedance spectra of all the anodes studied 
in the present work have a centre that lies under the real axis, which is the characteristic behaviour of Al-Zn alloys undergoing uniform galvanic dissolution (Noguchi et al., 1998).

A

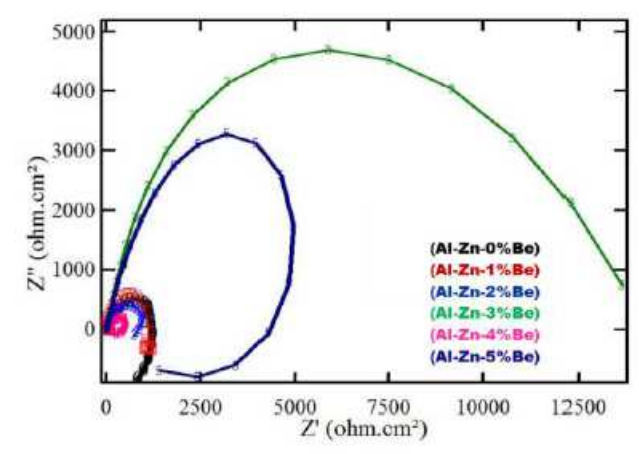

B

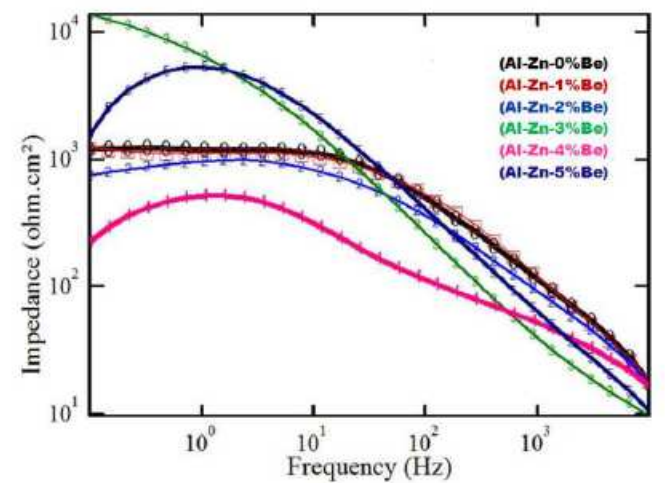

Figure 4. (A) Nyquist and (B) Bode plots for Al-5\% Zn alloy with Be.

The high frequency plot associated with the charge transfer process and the low frequency plot corresponds to mass transfer process. The semicircle at the high frequency was found to have similar behaviour, in spite of the variation in the beryllium content. The semicircle can be attributed to the formation of $\mathrm{Zn}(\mathrm{OH})_{2}$ and $\mathrm{Al}(\mathrm{OH})_{3}$ layers on the anode surface, due to the oxidation of $\mathrm{Zn}$ and $\mathrm{Al}$. The depression and pseudo inductive behaviour of the semicircles can be attributed to active dissolution (Barbucci et al., 1998). Depressed semicircle shape of the complex impedance plane is due to the inhomogeneity of the anode surface (Ramlet et al., 1990). The experimental data can be described using a simple equivalent circuit, and in this circuit $R_{s}$ is the solution resistance, $R_{p}$ is the polarization resistance, and $\mathrm{A}$ is the constant phase element (CPE) that is introduced for better data fitting instead of an ideal capacitance parameter. The impedance expression of CPE is defined as

$$
\mathrm{Z}_{\mathrm{CPE}}=\left[\mathrm{A}(\mathrm{jw})^{\mathrm{n}}\right]^{-1}
$$

where $\mathrm{A}$ and $\mathrm{n}$ are frequency independent fit parameters, $\mathrm{j}=(-1)^{1 / 2}$ and $\mathrm{w}=2 \Pi \mathrm{f}$, the frequency. Depending on the values of $n$, the CPE can represent resistance ( $n$ $=0$ and $\mathrm{A}=\mathrm{R})$, capacitance $(\mathrm{n}=1, \mathrm{~A}=\mathrm{C})$, inductance $(\mathrm{n}=-1, \mathrm{~A}=\mathrm{L})$ and Warburg impedance $(n=0.5$ and $A=W)$. CPE is related to some inhomogeneity on the surface of the anodes. From the impedance analysis, the total polarization resistance $\left(R_{p}\right)$ was a measure that constitutes the main practical parameter useful for the understanding of the anode dissolution rate. The "double layer capacitance" in real cells often behaves like a CPE, instead of like a capacitor.

Several theories have been proposed to account for the non-ideal behaviour of the double layer, but none has been universally accepted. In most cases, ' $n$ ' is treated as an empirical constant, and this does not have much physical basis. It is possible to study by EIS the behaviour of the oxide film on the anode surface, when it is exposed to an electrolyte. $R_{p}$ value is an indication of effective interaction between the oxide film and the substrate, which lowers the surface 
resistance, a requisite to sacrificial anodes (Talavera et al., 2002). Duplicate experiments were conducted, and the average values were compared. The $\mathrm{R}_{\mathrm{p}}$ value of beryllium incorporated alloys are in the order of $3 \%<4 \%<1 \%<2 \%<$ $5 \%$ (Table 4).

Table 4. Data derived from the impedance plot for beryllium incorporated Al-Zn5\% alloy anode.

\begin{tabular}{c|c|c|c|c|c|c}
\hline \multirow{2}{*}{$\begin{array}{c}\text { \% of } \\
\text { Beryllium }\end{array}$} & \multicolumn{7}{|c}{ Impedance parameters } \\
\cline { 2 - 7 } & $\begin{array}{c}\mathrm{R}_{\mathrm{s}} \\
\left(\mathrm{k} \Omega . \mathrm{cm}^{2}\right)\end{array}$ & $\begin{array}{c}\mathrm{R}_{\mathrm{ct}} \\
\left(\Omega \mathrm{cm}^{-2}\right)\end{array}$ & $\begin{array}{c}\mathrm{C}_{\mathrm{dl}} \\
\left(\Omega \mathrm{cm}^{-2}\right)\end{array}$ & $\begin{array}{c}\mathrm{R}_{\mathrm{p}} \\
\left(\Omega \mathrm{cm}^{2}\right)\end{array}$ & $\begin{array}{c}\mathrm{CPE} \\
\left(\mathrm{Fcm}^{-2}\right) \times 10^{-8}\end{array}$ & $\mathrm{n}$ \\
\hline 0 & $1.203 \times 10^{1}$ & $1.663 \times 10^{3}$ & $2.556 \times 10^{-5}$ & 80.103 & 1.074 & 1.293 \\
1 & $1.034 \times 10^{1}$ & $1.196 \times 10^{3}$ & $3.705 \times 10^{-4}$ & 80.389 & 1.103 & 1.292 \\
2 & $1.367 \times 10^{-1}$ & $1.007 \times 10^{3}$ & $1.644 \times 10^{-3}$ & 80.463 & 1.094 & 1.292 \\
3 & $1.621 \times 10^{1}$ & $8.993 \times 10^{2}$ & $2.909 \times 10^{-5}$ & 79.330 & 1.152 & 1.309 \\
4 & $9.901 \times 10^{0}$ & $1.281 \times 10^{4}$ & $1.215 \times 10^{-5}$ & 79.607 & 1.161 & 1.305 \\
5 & $5.501 \times 10^{-1}$ & $5.16 \times 10^{2}$ & $4.870 \times 10^{-5}$ & 87.215 & 1.055 & 1.289 \\
\hline
\end{tabular}

$\mathrm{R}_{\mathrm{p}}$ value is found to be minimum for $3 \%$ beryllium incorporated anodes. From the experimental data, it is clear that a higher and lower concentration of beryllium addition to the aluminium alloy resulted in a worse behaviour, but particle incorporation in between $3 \%$ and $5 \%$ resulted in an improvement in the performance of the anode.

\section{Conclusions}

Physico-chemical characteristics of the aluminium alloy anodes were significantly improved by the incorporation of beryllium in the anode matrix. The reinforcement of the $\mathrm{Al}+5 \% \mathrm{Zn}$ alloy anode with $5 \%$ beryllium increased the efficiency from 58.42 to $90.19 \%$. The $2 \%$ beryllium incorporated anode exhibited excellent electrochemical characteristics, and this concentration was selected as the optimized amount. The presence of beryllium in the anode matrix caused effective destruction of the passive alumina film. The destruction of alumina film facilitated the enhancement of galvanic performance of the anode. The moderator particles in the anode matrix effectively reduced the passive film on the anode surface. The anodes also have merits of low cost, easy development and moderate galvanic performance. The improved activity of the anodes can be used for the formation of modified anodes suitable for use in aggressive marine environments.

\section{Acknowledgements}

One of the authors, R. Natarajan, acknowledges to University Grants Commission, New Delhi India, for financial assistance. 


\section{References}

1. Genesca J, Juarez J. Development and testing of Galvanic anodes for cathodic protection. Contributions Sci. 2000;1:331.

2. Lyublinskii EY. Electrochemiya. 1973;9:461.

3. Reboul M, Gimenez P, Rameau JJ. A proposed activation mechanism for Al- Zn-In anodes", aluminium Pechiney. France: Centre de Recherches et de Development; 1982.

4. Li B, Logan BE. The impact of ultraviolet light on bacterial adhesion to glass and metal oxide-coated surface. Colloids Surf B: Biointerfaces. 2005; 41:153.

5. Shibli SMA, Gireesh VS. Activation of aluminium alloy sacrificial anodes by selenium. Corros Sci. 2005;47:2091.

6. Manoz AG,. Saidman SB, Bessone JB. Influence of In on the corrosion of Zn-In alloys. Corros Sci. 2001;43:1245.

7. Sun H, Liu L, Li Y, et al. The performance of Al-Zn-In-Mg-Ti sacrificial anode in simulated deep water environment. Corros Sci. 2013;77:77.

8. Shibli SMA, Gireesh VS, George S. Surface catalysis based on ruthenium dioxide for effective activation of aluminium sacrificial anodes. Corros Sci. 2004;46:819.

9. Maa J, Wena J. The effects of lanthanum on microstructure and electrochemical properties of Al-Zn-In based sacrificial anode alloys. Corros Sci. 2009;51:2115.

10. Khireche S, Boughrara D, Kadri A, et al. Corrosion mechanism of Al, Al$\mathrm{Zn}$ and $\mathrm{Al}-\mathrm{Zn}-\mathrm{Sn}$ alloys in $3 \mathrm{wt} . \% \mathrm{NaCl}$ solution. Corros Sci. 2014;87:504.

11. Jingling MA, Jiuba W, Gengxin LI, et al. The corrosion behaviour of AlZn-In-Mg-Ti alloy in NaCl solution. Corros Sci. 2010;52:534.

12. Saeri MR, Keyvani A. Optimization of Manganese and Magnesium Contents in As-cast Aluminum-Zinc-Indium Alloy as Sacrificial Anode. J Mater Sci Technol. 2011;27:785.

13. Sina H, Emamy M, Saremi M, et al. The influence of $\mathrm{Ti}$ and $\mathrm{Zr}$ on electrochemical properties of aluminum sacrificial anodes. Mater Sci Eng A. 2006;431:263.

14. Gudic S, Smoljko I, Kliskic M. The effect of small addition of tin and indium on the corrosion behavior of aluminium in chloride solution. $\mathrm{J}$ Alloys Comp. 2010;505:54.

15. Alvarez O, Gonzalez C, Aramburo G, et al. Characterization and prediction of microstructure in Al-Zn-Mg alloys. Mater Sci. Eng A. 2005;402:320.

16. Wen J, He J, Lu X. Influence of silicon on the corrosion behaviour of AlZn-In-Mg-Ti sacrificial anode. Corros Sci. 2011;53:3861.

17. Mathiyarasu J, Nehru LC, Subramanian P, et al. Anti-Corros Methods Mater. 2001;48:324.

18. DNV Recommended Practice RP B401: Cathodic Protection Design. Hovik: Det Norske Veritas Industry AS; 1993.

19. NACE Standard Test Method: Impressed Current Laboratory Testing of Aluminium Alloy Anodes. NACE Standard TM0190-98. Houston, NACE International; 1998. 
20. Noguchi T, Sawanyama P, Shima AF, et al. Photocatalytic Degradation of Gaseous Formaldehyde Using $\mathrm{TiO}_{2}$ Film. Environ Sci Technol. 1998;32:3831.

21. Barbucci A, Cerisola G, Cabot PL, et al. Electrochemical and morphologic investigation of Al-Mg-Zn alloys in artificial sea water. Mater Sci Forum 1998;289:529.

22. Ramlet V, Reinhard G. On the applicability of a constant phase element (CPE) to the estimation of roughness of solid metal electrodes. Electrochim Acta. 1990;35:1045-1049.

23. Talavera MV, Valdez S, Islas JAJ, et al. EIS testing of new aluminium sacrificial anodes. Appl Electrochem. 2002;32:897. 